\title{
Pesticide Residues Evaluation in Pulp, Juice and Nectar of Fruits
}

\author{
Claudia Helena Pastor Ciscato ${ }^{1}$, A. B. Gebara ${ }^{1}$, C. M. Barbosa ${ }^{1}$, G. S. Souza ${ }^{1}$, N. $\operatorname{Hamada}^{1}$ \& D. L. Silva ${ }^{1}$ \\ ${ }^{1}$ Pesticide Residues Laboratory, LRP, Biological Institute, Andar, SP, Brazil \\ Correspondence: Claudia Helena Pastor Ciscato, Pesticide Residues Laboratory, LRP, Biological Institute, Av: \\ Conselheiro Rodrigues Alves, 1252-3 Andar, CEP 04014-002, SP, Brazil. Tel: 55-11-5087-1732. E-mail: \\ ciscato@biologico.sp.gov.br
}

Received: October 22, 2011

Accepted: November 31, $2011 \quad$ Online Published: June 5, 2012

doi:10.5539/ep.v1n2p39

URL: http://dx.doi.org/10.5539/ep.v1n2p39

\begin{abstract}
Industrial processing of fruit in order to produce juice and nectar can contribute to over exposure of some contaminants, such as pesticide residues. Thus, this work aimed to check the compliance with the Maximum Residue Levels (MRL). In our research, 162 samples of frozen pulps, 16 of juice and 2 of nectar, were evaluated for pesticide residues, as well as the acceptable dietary intake (ADI). A multi-residue method was employed and almost 140 active ingredients were studied. Positive results were detected only in pulps, corresponding to $40 \%$ of the amount of samples. According to the Brazilian and the Codex Alimentarius legislation, none of the pesticide residues found were above the MRL. The most frequently found compounds were: pyridaphenthion, azinphos-methyl and carbendazim in peach and endosulfan in strawberry samples. Multiple findings were found in strawberry $(29.6 \%)$ and peach $(7.8 \%)$. Chronic dietary intake was not exceeded. The results demonstrated the necessity of pesticide residue control in fruit.
\end{abstract}

Keywords: pesticide, residue, fruit, pulp, juice, health risk

\section{Introduction}

In Brazil, the fresh fruit industrial processing to produce pulp, juice and nectar is an important agro-industry activity. Almost 1.6 million tones of juice are exported, being the orange juice the leader in the world trade. Such contribution corresponds to more than $80 \%$ of all fruit trading, what places Brazil as the main producer/exporter (Andrigueto, 2008).

Many fruits (tropical and temperate climate) are used in the industrial processing, such as banana, mango, orange, passion fruit, peach, pineapple and strawberry. The pulp has an extensive use in the food industry, especially when it comes to the production of nectar, juice, ice-cream, jelly and other fruit sweet products. Basically, the pulp is the product not fermented, which arose from the edible part of the fruit, after have being submitted to a typical process of cutting, milling and homogenization and preserved by a physical process as freezing. Following the pasteurization process, the pulp could be commercialized and used in juice or other preparations at restaurants, fast food restaurants, hospitals and also for home consumption.

It is important to highlight the fact that during the fruit production, 20 to $30 \%$ is destroyed, especially by pests' activities (IBGE, 2003). Therefore, in order to prevent and control the pests, some techniques including the pesticide usage are frequently applied. According to Garcia et al. (2005) in Brazil there are 367 active substances, which are distributed to 1045 formulated products such as insecticides, fungicides, herbicides, among other categories, comprehending all toxicological classes. Quality controls such as pesticide residues evaluation are parameters that should be verified to guarantee health food for the consumers. The presence of such chemical substances in foodstuffs promotes a health and economic impact

Finally, samples of pulp, juice and nectar were evaluated by pesticide residues contamination as well as their contribution to health risk.

\section{Material and Method}

\subsection{Chemicals and Samples}

All organic solvents and reagents were analytical grade from Tedia or Merck. Pesticide standards were from Ultra Scientific, AccuStandard, Dr. Ehrenstorfer and Riedel-de-Haën with around $99 \%$ of purity. 
The present study evaluated a total of 180 samples: 1. Pulp - acerola (5), apple (3), banana (3), caja (1), coconut (3), graviola (1), guava (4), mango (6), melon (3), papaya (4), passion fruit (16), peach (77), pear (5), pineapple (4) and strawberry (27), 2. Juice - guava (9), lemon (1) and orange (6), 3. Nectar - peach (2).

\subsection{Quality Control}

The validation study for the multiresidue method employed at Laboratorio de Residuos de Pesticidas (LRP) was accomplished with the criteria for analytical performance established from IUPAC Technical Report, 1999 (Thompson et al., 2002). The LRP participates in proficiency testing schemes on an annual basis with satisfactory performances. The recoveries are generally from 70 to $110 \%$.

The concentrations were calculated using a calibration curve generated from peak area, obtained by the results of standard injections. The quantification limit for organochlorine pesticides were $0.001 \mathrm{mg} / \mathrm{kg}$ and 0.01 to 0.05 $\mathrm{mg} / \mathrm{kg}$ for organophosphorus, carbamates, pyrethroids insecticides some herbicides and fungicides.

\subsection{Methodology}

The multi-residue method DFG S19 was employed (Specht, 1992 and Modular L.00.00.34) to check the contamination by pesticide residues. Almost 140 active ingredients were evaluated, including organochlorine, organophosphorus, pyrethroids, carbamates and others insecticides, some fungicides and herbicides.

In brief, the samples were committed, homogenized and an aliquot was extracted with acetone. Partitioning was employed with a solvent mixture of cyclohexane + ethyl acetate (1:1). The clean-up was performed using gel permeation chromatography (GPC) with Bio Beads ${ }^{\circledR}$ S-X3 polystyrene gel and an additional clean-up step with silica gel deactivated $1.5 \%$ was employed when necessary.

Identification and quantification of pesticides were carried out by GC with electron capture detector (ECD), nitrogen/phosphorus detector (NPD), flame photometric detector (FPD) and HPLC with UV/Vis and fluorescence detectors. All confirmations were carried out by LC/MS/MS.

Dithiocarbamates were determined by the DFG S15 (Specht, 1992), method with a modification using a vertical disulfide reaction system proposed by Caldas et al. (2000). An aliquot of $300 \mathrm{~g}$ of sample was heated with a solution of stannous chloride and hydrochloric acid. The carbon disulphide were distilled, purified and collected in an ethanol solution of cupric acetate and diethanolamide. A spectrophotometric method, using the visible range was employed for the determination of dithiocarbamates by $\mathrm{CS}_{2}$ conversion.

Dithiocarbamates fungicides were analyzed employing the spectrophotometer to determine the $\mathrm{CS}_{2}$ concentration (Caldas et al., 2001).

Positive results were compared with the Brazilian legislation (ANVISA, 2011) and international MRLs from Codex Alimentarius (CODEX, 2011).

Pesticide residue contribution to ADI (acceptable dietary intake) parameter was calculated employing the recommended World Health Organization procedure (GEMS/FOOD, 1997) and the results were calculated in $\mathrm{mg} /$ person/day or $\mathrm{mg} /$ body weight/day considering the body weight (b.w.) of an adult as $60 \mathrm{~kg}$.

Dietary exposure $=\sum$ concentration of chemical in food $\left(\mathrm{mg} \cdot \mathrm{kg}^{-1}\right) \mathrm{x}$ food consumption $(\mathrm{kg}) / \mathrm{b} . \mathrm{w}$.

The food consumption was evaluated according to data consumption from IBGE (2010) and GEMS/FOOD (2003) to regional diet.

The values from the dietary exposure were compared with the ADI $(\% \mathrm{ADI}<100)$ and the percentage of pesticide residue contribution was calculated as follows:

$\% \mathrm{ADI}=$ dietary exposure $\mathrm{x} 100 / \mathrm{ADI}$

\section{Results and Discussion}

Positive results were observed only in pulp samples, corresponding to $40 \%$ of the total amount of samples. The results according to national and international legislation are presented at Table 1 . None of the samples were contaminated by pesticide residues above the Maximum Residue Level (MRL) and pesticide residues below the MRL were found in 3.9\% and 12.2\%, according to Anvisa (2011) and Codex Alimentarius (2011).

The Table 2 presents the pesticide residues found in the samples, the levels and MRL from national and international legislation. The most frequent pesticide/commodity combination was: pyridaphenthion in peach (16), endosulfan in strawberry (15), azinphos-methyl in peach (12) and carbendazim in peach (10). According to the national and international legislation some of those, as azinphos ethyl, bromopropylate, carbaryl, 
chlorothalonil, dimethoate, endosulfan, pyridaphenthion, simazine and tetradifon have no MRL. Multiple findings were observed in strawberry and peach, $29.6 \%$ and $7.8 \%$.

Table 1 Pesticide residues results according to the Brazilian and the Codex Alimentarius legislation

\begin{tabular}{|c|c|c|c|c|c|c|c|}
\hline \multirow[t]{2}{*}{ Fruit sample } & \multirow[t]{2}{*}{ Total sample } & \multicolumn{2}{|c|}{$>$ MRL } & \multicolumn{2}{|c|}{$<\mathrm{MRL}$} & \multicolumn{2}{|c|}{ No MRL } \\
\hline & & BR & Codex & BR & Codex & BR & Codex \\
\hline Acerola & 5 & & & & & & \\
\hline Apple & 3 & & & 1 & & & 1 \\
\hline Banana & 1 & & & & & & \\
\hline Caja & 1 & & & & & & \\
\hline Coconut & 3 & & & & & & \\
\hline Graviola & 1 & & & & & & \\
\hline Guava & 4 & & & & & 2 & 2 \\
\hline Guava & 9 (juice) & & & & & & \\
\hline Lemon & 1 (juice) & & & & & & \\
\hline Mango & 6 & & & & & & \\
\hline Melon & 3 & & & & & & \\
\hline Orange & 6 (juice) & & & & & & \\
\hline Papaya & 4 & & & & & & \\
\hline Passion fruit & 16 & & & & & & \\
\hline Peach & 77 & & & 1 & 18 & 47 & 30 \\
\hline Peach & 2 (nectar) & & & & & & \\
\hline Pear & 5 & & & & & & \\
\hline Pineapple & 4 & & & & & & \\
\hline Strawberry & 27 & & & 5 & 4 & 16 & 17 \\
\hline Total samples & 180 & 0 & 0 & 7 & 22 & 65 & 50 \\
\hline Total \% & 100 & 0 & 0 & 3.9 & 12.2 & 36.1 & 27.8 \\
\hline
\end{tabular}

Table 2. Pesticide residues levels found and the MRL from Brazilian and Codex Alimentarius legislation

\begin{tabular}{|c|c|c|c|c|c|c|c|c|c|}
\hline \multirow[t]{2}{*}{ Pesticide found } & \multirow[t]{2}{*}{$\begin{array}{l}\leq \\
0.01\end{array}$} & \multirow[t]{2}{*}{$\begin{array}{l}> \\
0.01-0.05\end{array}$} & \multirow[t]{2}{*}{$>0.05-0.2$} & \multirow[t]{2}{*}{$>0.2-0.4$} & \multirow[t]{2}{*}{$>0.4-0.8$} & \multirow[t]{2}{*}{$\begin{array}{l}> \\
0.8-1.0\end{array}$} & \multicolumn{2}{|l|}{ MRL } & \multirow[t]{2}{*}{ Commodity } \\
\hline & & & & & & & $\mathrm{BR}$ & Codex & \\
\hline Azinphos-ethyl & & 6 & & & & & NPC & NPC & peach \\
\hline Azinphos-methyl & 2 & 6 & 4 & & & & NPC & 2.0 & peach \\
\hline Bifenthrin & 2 & & & & & & NPC & 1.0 & strawberry \\
\hline Bromopropylate & 1 & & & & & & NPC & NPC & strawberry \\
\hline Captan & & & 1 & 2 & 1 & & NPC & 15.0 & strawberry \\
\hline Carbaryl & 2 & 1 & & & & & NPC & NPC & peach \\
\hline Carbendazim & 9 & & 1 & & & & NPC & 2.0 & peach \\
\hline & & 1 & 1 & & & & 5.0 & NPC & strawberry \\
\hline Chlorothalonil & 2 & 2 & & & & & NPC & NPC & strawberry \\
\hline Chlorpyrifos & & 1 & & & & & 1.0 & NPC & apple \\
\hline Diazinon & & & 1 & & & & NPC & 0.1 & strawberry \\
\hline Dimethoate & & & 2 & 1 & & & NPC & NPC & $\begin{array}{l}\text { Guava and } \\
\text { peach }\end{array}$ \\
\hline Dithiocarbamates & & & 1 & & & & 2.0 & NPC & peach \\
\hline Endosulfan & 7 & 7 & 1 & & & & NPC & NPC & strawberry \\
\hline Fenpropathrin & 1 & 1 & 1 & 1 & & & 2.0 & NPC & strawberry \\
\hline Fluazinam & & 2 & 2 & 1 & & & 2.0 & NPC & strawberry \\
\hline Folpet & 1 & & & & & & NPC & 15.0 & strawberry \\
\hline Iprodione & & 1 & 2 & 3 & & & 2.0 & 10.0 & strawberry \\
\hline Malathion & & 1 & 1 & & & & 1.0 & 1.0 & strawberry \\
\hline Procymidone & 2 & & 4 & 1 & & 1 & 3.0 & 10.0 & strawberry \\
\hline Pyridafenthion & 6 & 10 & & & & & NPC & NPC & peach \\
\hline Simazine & & & & 1 & & & NPC & NPC & strawberry \\
\hline Tetradifon & 2 & 2 & & & & & NPC & NPC & strawberry \\
\hline
\end{tabular}


The results are very similar to those observed in fruit samples from national data (Gebara et al., 2005a, 2005b, 2008, Cantarutti et al., 2008, Ciscato et al., 2009, PARA, 2001-2009). International data from pesticide monitoring programs (FDA, 2007; EFSA, 2008), presented pesticide residues at or below the MRL (35\%), above the MRL ( $2 \%)$ and with no detectable residues $(60 \%)$.

Caldas and Souza, 2000, observed that some crops as rice, beans, fruit, especially citrus and tomato, were the most important in pesticide residue contamination, as well as the surpassing of the ADI parameter. The authors suggested that the Brazilian legislation does not contemplate the risk assessment during the pesticide registration process. The same scenery was observed by Enes et al. (2005).

The ADI parameter in this study was not exceeded in any samples. The greater value was observed only for azinphos-methyl in one peach sample (26.9\%). The other compounds did not contribute more than $4 \%$ of ADI and $<0.5 \%$ considering the acute reference parameter (dimethoate, carbendazim, chlorpyrifos, endosulfan, folpet, captan, diazinon and malathion). It is worthwhile to point out that their contribution to health risk, even for the more sensible consumers, was not significant.

Jardim and Caldas (2009) attributed the differences in the ADI values between national and international data for some substances, as observed in this study (azinphos-methyl, carbaryl and carbendazim) to the differences in the toxicological criteria employed during the evaluation process by the governmental agencies. A surpass on ADI parameter does not represent pesticide residues above the MRL. In such case, the dietary data of consumption should be revised.

Multiple findings observed in peach and strawberry could contribute to a health risk for the consumers. Boobis et al. (2008) highlighted that the presence of compounds which belong to the same chemical group could contribute to a cumulative effect.

Pesticide residues studies provide an important data about food quality and food production. Currently in Brazil, fruit production is using the Integrated Production of Fruit (IPF), whose pesticide management contributes to reduce the pesticide contamination comparing to conventional agriculture (Andrigueto et al., 2005). Cruz et al. (2006) indicates the good agricultural practices as an important prerequisite in food production, suggesting that pesticide residues data are an input in such project.

\section{Conclusion}

In spite of the positive results found in the samples, the national and international MRLs were not exceeded. Most of the pesticides found in the samples corresponded to organophosphate group. Peach and strawberry samples were the most important commodities, which were contaminated by pesticide residues.

The ADI parameter evaluated in this study were not surpassed, all results were $<100 \%$ of ADI. It could be emphasized that the samples did not contribute to a health risk. Some pesticides, according to the national and international legislation, do not have a MRL established to the crop and this result showed the necessity of a continuous evaluation of the pesticide usage, especially to the pulps of guava, peach and strawberry, which are prepared by a simple homogenizing process (peal and flesh).

The goal on fruit production is the continuous effort in quality and safe products for the consumers. Brazil, as a great producer and exporter, should associate this safe parameter in order to obtain sustainable fruit production, so that it can increase its participation on national and international market (Nacheruber et al., 2009; Sansavinf, 2006).

\section{References}

Andrigueto, J. R., Nasser, L. C. B., \& Teixeira, J. M. A. (2005). Produção integrada de frutas: conceito, histórico e a evolução para o sistema agropecuário de produção integrada - SAPI.

Andrigueto, J. R., Nasser, L. C. B., Teixeira, J. M. A., Simon, G., Veras, M. C.V., Medeiros, S. A. F., Souto, R., ... Kososki, A. R. (2008). Produção Integrada de Frutas e Sistema Agropecuário de Produção Integrada no Brasil.

ANVISA. (2011). Agência Nacional de Vigilância Sanitária - Monografias - Agrotóxicos. Retrieved from http://portal.anvisa.gov.br/wps/portal/anvisa/home/agrotoxicotoxicologia?ta=agrotoxico

ANVISA. (2011). Agência Nacional de Vigilância Sanitária - PARA (Programa de Análise de Resíduos de Agrotóxicos em alimentos). Retrieved from http://www.anvisa.gov.br/toxicologia/residuos/index.htm 
Boobis, A. R., Ossendorpb, B. C., Banasiakc, U., Hameyd, P. Y, Sebestyen I., \& Morettof, A. (2008). Cumulative risk assessment of pesticide residues in food. Toxicology Letters, 180, 137-150. http://dx.doi.org/10.1016/j.toxlet.2008.06.004

Caldas, E. D., \& Souza, L. C. K. (2000). Avaliação de risco crônico da ingestão de resíduos de pesticidas na dieta brasileira. Rev. Saúde Pública, Journal of Public Health, 34(5), 529-37.

Caldas, E. D., Conceição, M. H., Miranda, M. C., Souza, L. C. K. R., \& Lima, J. F. (2001). Determination of dithiocarbamate fungicide residue in food by a spectrophotometric method using a vertical disulphide reaction system. Journal of Agricultural and Food Chemistry, 49(10), 4521-4525. http://dx.doi.org/10.1021/jf010124a

Cantarutti, T. F. P., Araujo, S. L., Rossi, S. C., \& Salsenter, P. R. (2008). Resíduos de Pesticidas em alimentos. Rev. Ecotoxicologia e meio ambiente, 18, 9-16.

Ciscato, C. H. P., Gebara, A. B., \& Monteiro, S. H. (2009). Pesticide residue monitoring of Brazilian fruit for export 2006-2007. Food Additives and Contaminants: Part B, 2(2), 140-145. http://dx.doi.org/10.1080/19440040903330326

Codex Alimentarius. (2011). Pesticide residues in Food and Feed - Codex Pesticides Residues in Food on line Database. Retrieve from http://www.codexalimentarius.net/pestres/data/index.html

Cruz, A. G., Cenci, S. A., \& Maia, M. C. A. (2006). Good agricultural practices in a Brazilian produce plant. Food Control, 17, 781-788. http://dx.doi.org/10.1016/j.foodcont.2005.05.002

DFG. (2009). Modular Multiple Revised Version of the DFG METHOD S19. Modular multiple analytical method for the determination of pesticide residues in foodstuffs. Collection of Official Methods under article 35 of the German Federal Food Act as method L00.00-34 (1999). Retriever from http://www.methodensammlung-bvl.de/cn/bGV2ZWw9dHBsLXN1Y2hlcmdlYm5pcyZsaW1pdGF0aW9ud H1wZT0mc2VhcmNoYWNjZXNza2V5PUNPT1RFT1QmeGFnZW1kPTY*.html

EFSA. (2008). European Food Safety Authority. Annual Report on Pesticide Residues According to Article 32 of Regulation (EC) nº 396/2005. 2010. EFSA Journal, 8(7), 1646.

FDA. (2011). U.S. Food and Drug Administration. Pesticide monitoring. Program FY 2007 Retrieve from http://www.fda.gov/Food/FoodSafety/FoodContaminantsAdulteration/Pesticides/ResidueMonitoringReport s/ucm169577.htm

Garcia, E. G., Bussacos, M. A., \& Fisher, F. M. (2005). Impacto da legislação no registro de agrotóxicos de maior toxicidade no Brasil. Rev. Saúde Pública, 39(5), 832-9. http://dx.doi.org/10.1590/S0034-89102005000500020

Gebara, A. B., Ciscato, C. H. P., Ferreira, M. S., \& Monteiro, S. H. (2005a). Pesticide residues in vegetables and fruits monitored in São Paulo City, Brazil, 1994-2001. Bull Environm Contam Toxicol, 75, 163-169. http://dx.doi.org/10.1007/s00128-005-0733-9

Gebara, A. B., Ciscato, C. H. P., Ferreira, M. S., \& Monteiro, S. H. (2008). Pesticide residues evaluation in fruit samples commercialized in São Paulo city, Brazil, 2002-2005. Rev. Bras. Toxicologia, 21(2), 87-92.

Gebara, A. B., Ciscato, C. H. P., \& Ferreira, M. S. (2005b). Design and Implementation of an Effective Regional Monitoring program for Pesticide Residues in Food. Proceeding of IUPAC-UCR-MAG Int'1 Workshop on Crop Protection chemistry. Feb. 14-17, San Jose, Costa Rica, 159-163.

GEMS/FOOD. (1997). Guidelines for predicting dietary intake of pesticide residues (revised). Prepared by the Global Environment Monitoring System - Food Contamination Monitoring and Assessment Program (GEMS/FOOD) in collaboration with the Codex Committee on Pesticide Residues.

GEMS/FOOD. (2011). Regional per Capita Consumption of Raw and Semi processed Agricultural Commodities. 2003. http://www.foodrisk.umd.edu/resource_types/databases/commodities.cfm?keyword=General

IBGE. (2009). Ministério do Planejamento e Gestão (Instituto Brasileiro de Geografia e Estatística) -

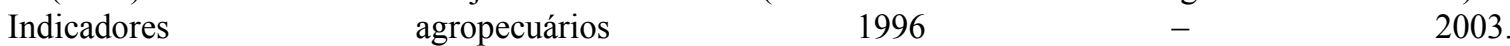
http://www1.ibge.gov.br/home/presidencia/noticias/noticia_visualiza.php?id_noticia=330\&id_pagina=1

IBGE. (2011). Ministério do Planejamento e Gestão (Instituto Brasileiro de Geografia e Estatística) - Pesquisa de Orçamentos Familiares 2008-2009 - Análise do Consumo Alimentar Pessoal no Brasil, RJ. http://www.ibge.gov.br/home/estatistica/populacao/condicaodevida/pdf/2008-2009_analise-consumo/defaul tlab_pdf_energia 
Jardim, A. N. O., \& Caldas, E. D. (2009). Exposição humana a substâncias químicas potencialmente tóxicas na dieta e os riscos para a saúde. Química Nova, 32(7), 1898-1909. http://dx.doi.org/10.1590/S0100-40422009000700036

Nahreiner, M. L., Santos, R. R. P. dos, Boteonim, M. Janelas de mercado. (2011). A fruticultura brasileira no mercado internacional. Retrieved from http://www.cepea.esalq.usp.br/pdf/janelas.pdf

Sansavinf, S. (2006). The role of research and technology in shaping a sustainable fruit industry: European advances and prospects. Rev. Bras. Frutic, 28(3), 550-558. http://dx.doi.org/10.1590/S0100-29452006000300049

Specht, W. (1992). Organochlorine, organophosphorus, nitrogen-containing and other pesticide. In Manual of Pesticide Residues Analysis, DFG, Deutsche Forchungsgenneubschaft, Pesticide Commission, VHC. New York: Weinfeim (Germany) - VCH, Publishers In.

Thompson, M., Ellison, S. L. R., \& Woos, R. (2002). Harmonized guidelines for single-laboratory validation of methods of analysis (IUPA Technical Report, 1999). Pure Applied Chemistry, 74(5), 835-855. http://dx.doi.org/10.1351/pac200274050835 